Provided for non-commercial research and education use. Not for reproduction, distribution or commercial use.

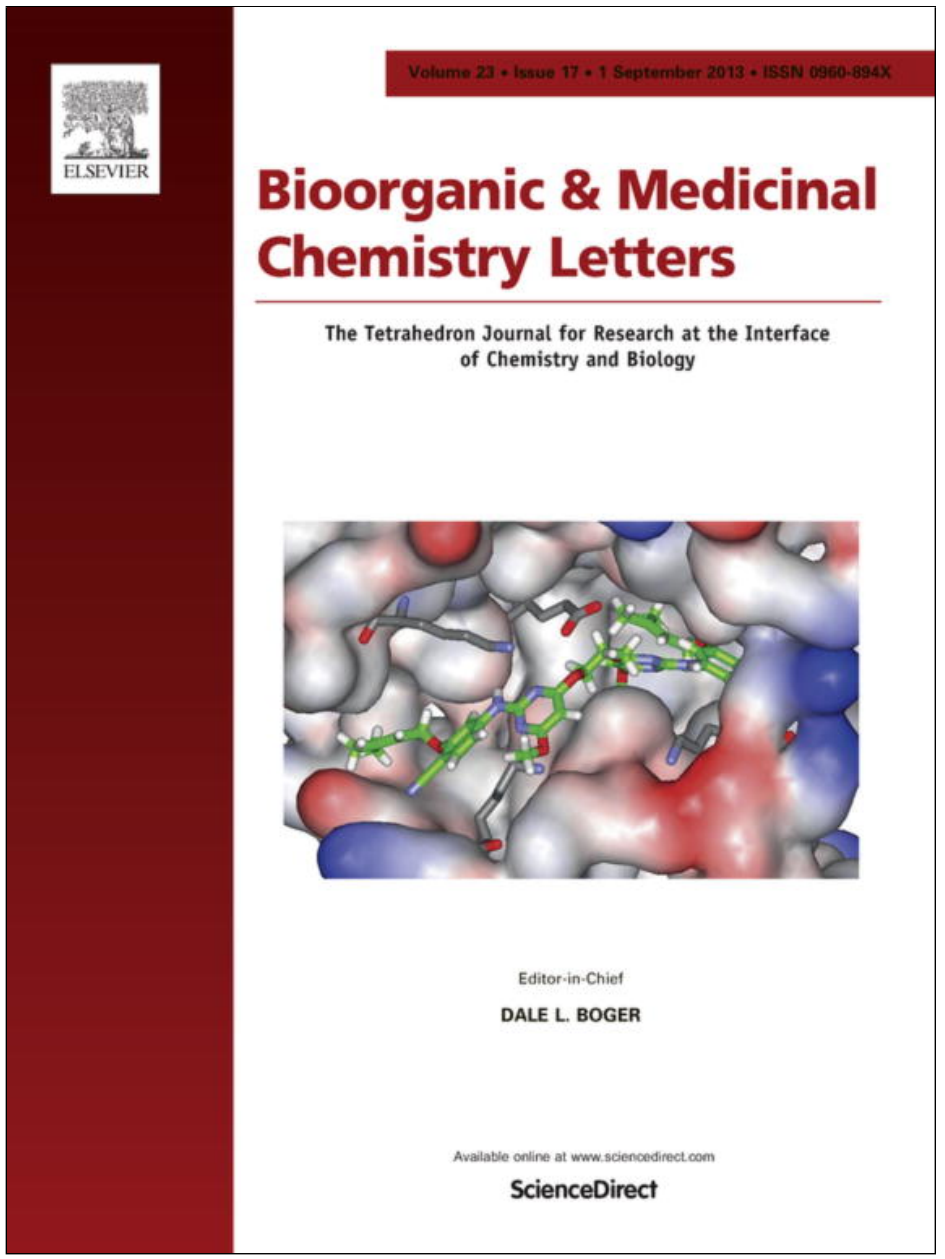

This article appeared in a journal published by Elsevier. The attached copy is furnished to the author for internal non-commercial research and education use, including for instruction at the authors institution and sharing with colleagues.

Other uses, including reproduction and distribution, or selling or licensing copies, or posting to personal, institutional or third party websites are prohibited.

In most cases authors are permitted to post their version of the article (e.g. in Word or Tex form) to their personal website or institutional repository. Authors requiring further information regarding Elsevier's archiving and manuscript policies are encouraged to visit:

http://www.elsevier.com/authorsrights 


\title{
Convenient synthesis of heterobifunctional poly(ethylene glycol) suitable for the functionalization of iron oxide nanoparticles for biomedical applications
}

\author{
Solène Passemard ${ }^{a}$, Davide Staedler ${ }^{a}$, Lucia Učňováa ${ }^{a}$, Guillaume Stéphane Schneiter ${ }^{a}$, Phally Kong ${ }^{a}$, \\ Luigi Bonacina $^{\mathrm{b}}$, Lucienne Juillerat-Jeanneret ${ }^{\mathrm{c}}$, Sandrine Gerber-Lemaire ${ }^{\mathrm{a}, *}$ \\ ${ }^{a}$ Laboratory of Synthesis and Natural Products, Institute of Chemical Sciences and Engineering, Ecole Polytechnique Fédérale de Lausanne, Batochime, CH-1015 Lausanne, Switzerland \\ ${ }^{\mathrm{b}}$ GAP-Biophotonics, Université de Genève, 22 Chemin de Pinchat, CH-1211 Genève 4, Switzerland \\ ${ }^{c}$ Centre Hospitalier Universitaire Vaudois and Institute of Pathology, University of Lausanne, Rue du Bugnon 25, CH-1011 Lausanne, Switzerland
}

\section{A R T I C L E I N F O}

\section{Article history:}

Received 10 April 2013

Revised 10 June 2013

Accepted 12 June 2013

Available online 25 June 2013

\section{Keywords:}

Functionalized nanoparticles

Heterotelechelic PEG oligomer

Pegylation

Selective monoreduction

Cancer cells targeting

USPIO NPs

\begin{abstract}
A B S T R A C T
A straightforward route is proposed for the multi-gram scale synthesis of heterobifunctional poly(ethylene glycol) (PEG) oligomers containing combination of triethyloxysilane extremity for surface modification of metal oxides and amino or azido active end groups for further functionalization. The suitability of these PEG derivatives to be conjugated to nanomaterials was shown by pegylation of ultrasmall superparamagnetic iron oxide (USPIO) nanoparticles (NPs), followed by functionalization with small peptide ligands for biomedical applications.
\end{abstract}

(c) 2013 Elsevier Ltd. All rights reserved.
Poly(ethylene glycol) (PEG) has recently emerged as oligomer of choice for diverse applications in biomedical areas, such as surface modification, functionalization of nanomaterials and biomolecules. ${ }^{1}$ Due to the remarkable properties of PEG oligomers, including nontoxicity, nonimmunogenicity, biocompatibility and high solubility in many organic solvents and in aqueous media, pegylation has been extensively used to increase the performance of surfaces and macromolecules. In particular, pegylated nanocarriers demonstrated high efficiency for the improved delivery of small molecule effectors, ${ }^{2-4}$ proteins ${ }^{5,6}$ or $\mathrm{DNA}^{7,8}$ to their target receptors. These sophisticated applications require the access to PEG molecules presenting two orthogonal and reactive end functionalities. ${ }^{1}$ The most common route to these hetero-bifunctional PEG relies on anionic polymerization of ethylene oxide from functional initiators followed by post-modification of the terminal hydroxyl group. ${ }^{9-14}$ Other techniques include the modification of commercially available, but expensive, modified PEG molecules ${ }^{15-17}$ or the sequential and unsymmetrical alteration of end hydroxyl groups of linear PEG. In particular, the use of tosylate activating groups was reported by Mahou and Wandrey ${ }^{18}$ for the generation of diverse heterotelechelic PEG oligomers. Polymer-supported

\footnotetext{
* Corresponding author. Tel.: +41 2169393 72; fax: +41 216939355

E-mail address: Sandrine.Gerber@epfl.ch (S. Gerber-Lemaire).
}

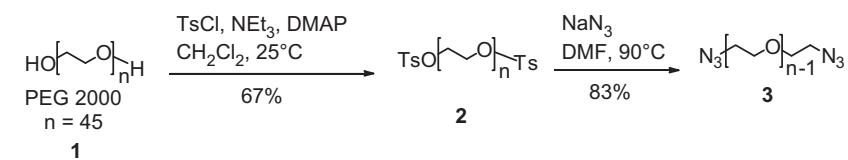

1

$\mathrm{PPh}_{3}, \mathrm{H}_{2} \mathrm{O}$

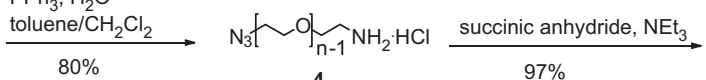

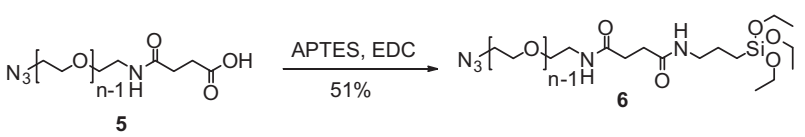

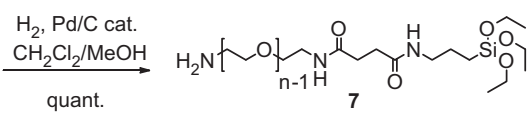

Scheme 1. Synthesis of heterobifunctional PEG derivatives.

pathway was also reported for the production of pyridyldithio activated PEG. ${ }^{19}$

We present herein an alternative approach for the multi-gram scale production of azido- and amino-silanized PEG molecules 


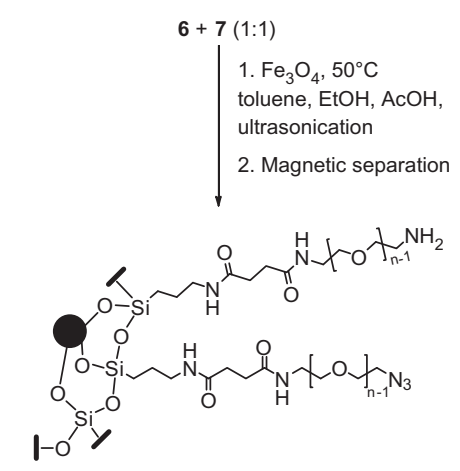

Scheme 2. Silanization of bare magnetite NPs.

Table 1

Mean DLS size (size distribution by number) and surface charge (zeta potential) of coated magnetite NPs

\begin{tabular}{llrl}
\hline Entry & Ratio $6: 7$ & \multicolumn{1}{c}{ DLS $(\mathrm{nm})$} & Zeta potential $(\mathrm{mV})$ \\
\hline 1 & $0: 0$ & $39.1 \pm 0.8$ & $-25.0 \pm 4.8$ \\
2 & $50: 50$ & $81.0 \pm 5.6$ & $+41.1 \pm 0.4$ \\
3 & $100: 0$ & $317.1 \pm 5.9$ & $+29.7 \pm 1.7$ \\
4 & $0: 100$ & $49.2 \pm 7.6$ & $+37.3 \pm 0.6$ \\
\hline
\end{tabular}

and their conjugation to ultrasmall superparamagnetic iron oxide (USPIO) nanoparticles (NPs) as model nanoparticles to highlight the potential of these heterobifunctional systems for the functionalization of nanomaterials. PEG-functionalized USPIO NPs (cNPs) were further conjugated with a $\mathrm{c}(\mathrm{RGDfK})$ moiety for the specific targeting of the cell membrane receptor $\alpha_{\mathrm{v}} \beta_{3}$ integrin. ${ }^{20-25}$

The synthesis of PEG tethers for surface modification of NPs requires a functional group at one end for conjugation to the material surface and a reactive group at the other end for functionalization with bioactive molecules. The preparation of $\alpha$-triethoxysilyl- $\omega$-amino PEG was thus envisaged for surface modification of USPIO NPs (see Supporting information for experimental procedures and characterizations). The sequential and unsymmetrical alteration of the end hydroxyl groups of linear PEG (PEG-2000, 2000 M W, 45 units) was achieved through semi-reduction of key intermediate 3 (Scheme 1). This diazido PEG derivative was obtained by ditosylation of PEG-2000 followed by nucleophilic displacement with sodium azide. This sequence could be achieved on up to $100 \mathrm{~g}$ of
PEG starting material with filtration of ditosylate $\mathbf{2}$ on silica gel as only purification step. Several reports proposed monotosylation of PEG ${ }^{18,26,27}$ as desymmetrization step but we experienced difficulties to obtain pure monotosylate intermediate on large scale and thus opted for monoreduction of $\mathbf{3}$ as desymmetrization pathway. Treatment of diazide 3 with triphenylphosphine (1 equiv), in acidic medium, afforded $\alpha$-amino- $\omega$-azido PEG 4 in high yield and excellent purity. The amino end was further reacted with succinic anhydride in almost quantitative yield, followed by coupling with 3-amino-propyltriethoxysilane to provide intermediate $\mathbf{6}$. The end azido group was reduced by hydrogenolysis to deliver $\alpha$-triethoxysilyl- $\omega$-amino PEG 7 in quantitative yield.

This straightforward route gives access to heterobifunctional PEG derivatives suitable for further conjugation to nanomaterials as the silyl functionality is a very efficient anchoring group for the pegylation of metal oxides, leading to highly stable coating in aqueous media. ${ }^{28}$ In addition, the amino or azido end groups can be coupled to biomolecules though peptide type coupling or copper-catalyzed [3+2] cycloadditions (click reactions). Other anchoring moieties such as carboxylates, phosphonates and catechol ligands, in particular dopamine-based derivatives, have been conjugated to nanoparticulate iron oxides ${ }^{29}$ to increase long-term colloidal stability in biological medium ${ }^{30}$ and to display multifunctional surfaces. ${ }^{31}$ Nevertheless, Fe(III)-mediated oxidation of catechol ligands might induce loss of colloidal stability and produce cytotoxic iron-quinone complexes. ${ }^{32}$

The suitability of heterobifunctional PEG molecules $\mathbf{6}$ and $\mathbf{7}$ for the pegylation of metal oxide NPs was addressed using USPIO NPs. A suspension of magnetite $\left(\mathrm{Fe}_{3} \mathrm{O}_{4}\right)$ NPs (PlasmaChem, $\sim 7 \%$ nanosuspension in water, average particle core size $8 \pm 3 \mathrm{~nm}$ ), in a mixture of $\mathrm{EtOH} /$ toluene $(1: 1)$, was ultrasonicated in the presence of AcOH and PEG derivatives 6 and 7 (1:1). After thorough washings with EtOH, using magnetic immobilization to separate the NPs from the supernatant, the coated NPs (cNPs) were suspended in EtOH (Scheme 2).

The cNPs were characterized for their size and surface charge by measurement of mean hydrodynamic diameter (dynamic light scattering) and zeta potential. Upon coating, the zeta potential value shifted from $-25.0 \pm 4.8$ to $+41.1 \pm 0.4 \mathrm{mV}$ and the mean hydrodynamic diameter increased from $39.1 \pm 0.8$ to $81 \pm 5.6 \mathrm{~nm}$ (Table 1, entries 1 and 2 and see Supplementary information). In addition, FT-IR spectrum of cNPs displayed bands at 3450-3350 and around $2100 \mathrm{~cm}^{-1}$ characteristic for amine and azide functionalities, respectively (Fig. 1). These results provide evidence for silanization of magnetite NPs with heterobifunctional PEG molecules

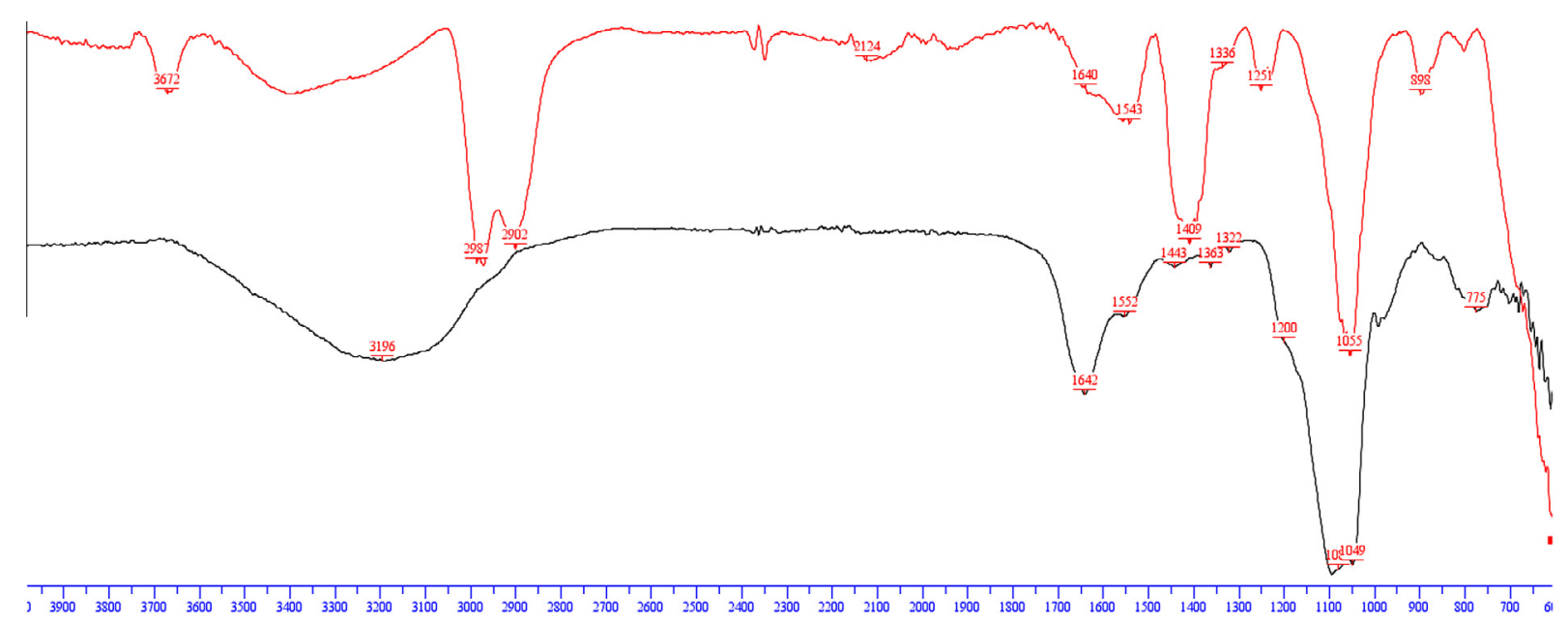

Figure 1. FT-IR of USPIO NPs coated with a (1:1) mixture of $\mathbf{6}$ and $\mathbf{7}$ (red) and functionalized NPs after click-reaction (black). 

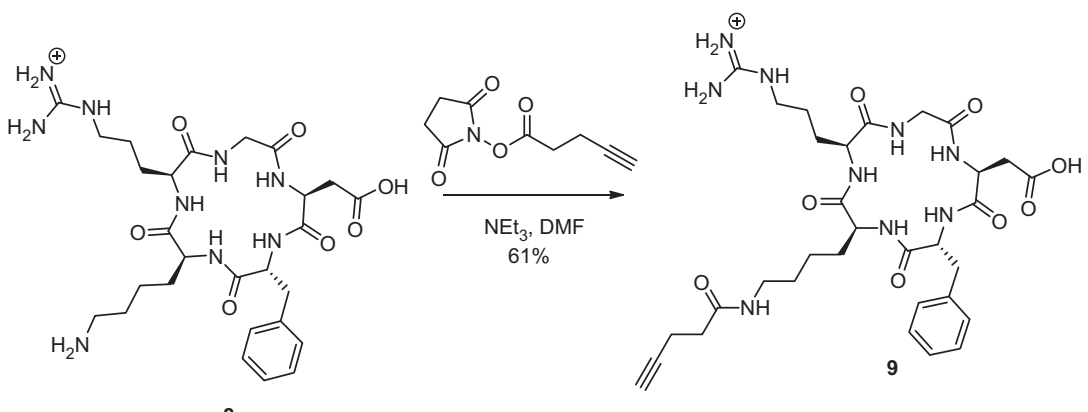

8

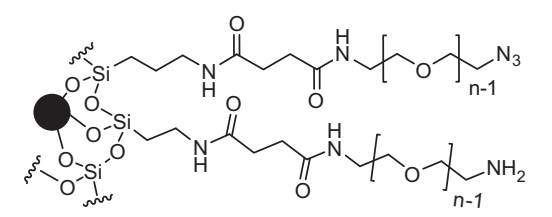

9. $\mathrm{CuSO}_{4}$

Sodium ascorbate

$\overrightarrow{\mathrm{H}_{2} \mathrm{O} \text {, DMF, ultrasonication }}$

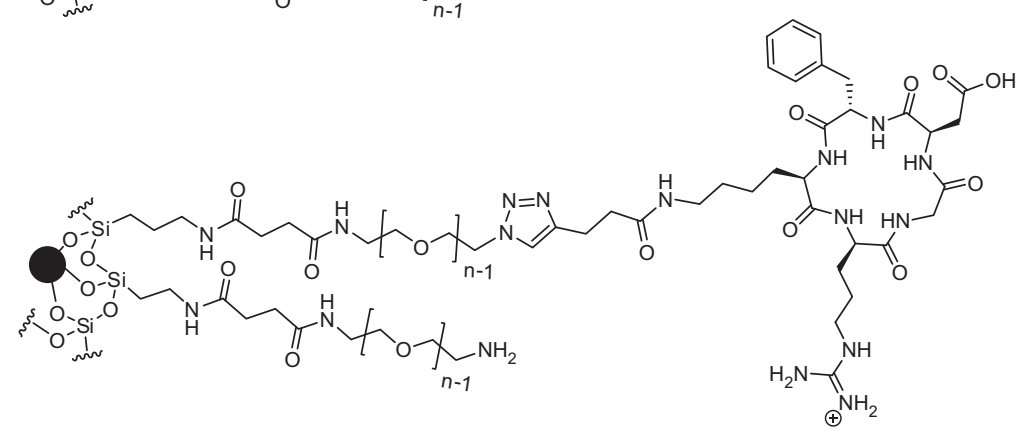

Scheme 3. Functionalization of the PEG-magnetite NPs with the $\alpha_{\mathrm{v}} \beta_{3}$ integrin-targeting ligand.

6 and 7. Upon pegylation with PEG oligomer 6 only, the resulting cNPs displayed a broad range of hydrodynamic diameters due to the formation of aggregates (Table 1, entry 3). The concomitant surface modification by both oligomers $\mathbf{6}$ and $\mathbf{7}$ resulted in polydisperse cNPs due to the presence of amine functionalities (Table 1 , entry 4). A (1:1) ratio of PEG derivatives 6 and 7 was thus selected to maintain a small hydrodynamic radius of the resulted cNPs and to display reactive surface azides for further functionalization.

In order to assess the suitability of the coated magnetite NPs for biomedical applications, the stability of surface coating with a (1:1) mixture of PEG derivatives $\mathbf{6}$ and $\mathbf{7}$ was evaluated at limit $\mathrm{pH}$ values encountered in cell culture media and biological environment. cNPs were suspended for $72 \mathrm{~h}$ in buffered solutions at $\mathrm{pH} 4$ (phosphate buffer) and $\mathrm{pH} 8(25 \mathrm{mM}$ Tris-HCl adjusted with $2 \mathrm{M} \mathrm{NaOH}$ ). After washing with EtOH, surface charge of the resulting nanoparticles was analyzed and resulted in zeta potential values of $+26.0 \pm 0.2$ and $+29.7 \pm 6.1 \mathrm{mV}$, respectively. These results gave evidence for stability of the surface coating in the range of pHs relevant for biomedical applications.

Conjugation to targeting entities was then investigated using the azide moieties as reactive partners for click reaction. The preparation of CRGDfK (8) was performed by solid phase peptide synthesis as previously described. ${ }^{33}$ The introduction of an alkynyl moiety was carried out by coupling with activated ester of pentynoic acid to afford intermediate $\mathbf{9}$ in $61 \%$ yield (Scheme 3). The azide-alkyne Huisgen's cycloaddition reaction was designed to occur at the interface of azide-PEG coating of the NPs suspended in $\mathrm{H}_{2} \mathrm{O}$. Ligand 9, dissolved in DMF, was added to a suspension of cNPs and the mixture was ultrasonicated for $12 \mathrm{~h}$ in the presence of copper sulfate and sodium ascorbate. The remaining copper species were removed by treatment with Cyclam, ${ }^{34}$ followed by thorough washing with methanol, using magnetic immobilization of the functionalized NPs.
The conjugation of cRGDfK to the surface of cNPs was monitored by FT-IR (Fig. 1). The presence of the peptide ligand was evidenced by bands at 1640 and $1550 \mathrm{~cm}^{-1}$, while the formation of the triazole unit was evidenced by the apparition of the $\mathrm{C}-\mathrm{N}$ stretching band at $1360 \mathrm{~cm}^{-1} .35$ The conjugated NPs were also characterized for their mean hydrodynamic diameter and surface charge which were measured at $137 \pm 29.5 \mathrm{~nm}$ and $+25 \pm 0.2 \mathrm{mV}$, respectively.

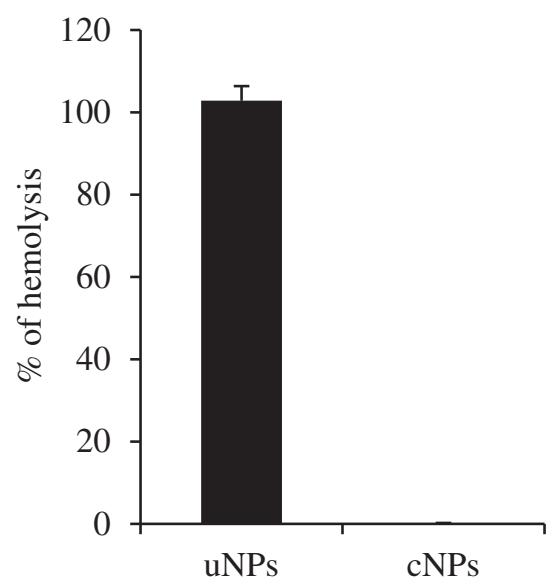

Figure 2. Hemolytic effect of bare and functionalized USPIO NPs on human red blood cells. Human red blood cells were exposed for $2 \mathrm{~h}$ either to unfunctionalized (uNPs) or to PEG-functionalized USPIO (cNPs) at a concentration of $50 \mu \mathrm{g} / \mathrm{mL}$, then the release of hemoglobin was assessed. Results are the mean \pm SD of triplicates of two independent experiments. NPs-exposed cells were compared to unexposed cells using a Student $t$-test: ${ }^{* * *} P<0.001$. 
PC3
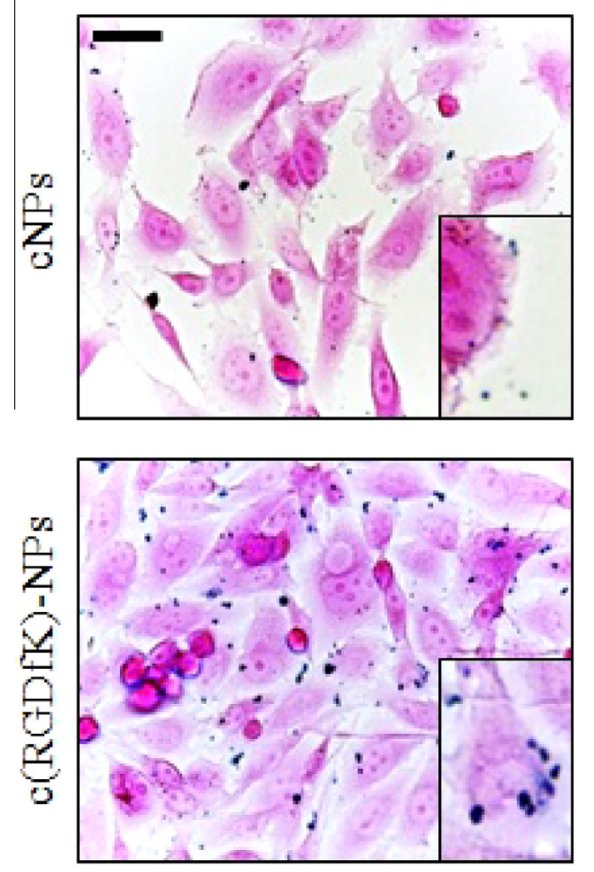

MCF-7
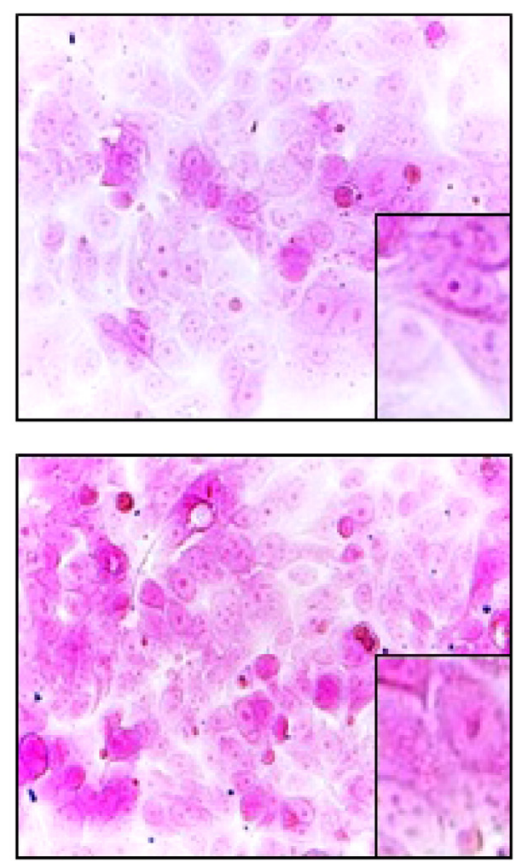

Figure 3. $\mathrm{c}$ (RGDfK)-USPIO NPs association with human PC3 and MCF-7 cancer cells. c(RGDfK)-USPIO NPs specifically bind to human prostate-derived PC 3 expressing the $\alpha_{\mathrm{v}} \beta_{3}$ integrin, but not the breast-derived MCF-7 cells, not expressing this integrin. PC3 and MCF-7 cells were incubated for $30 \mathrm{~min}$ in the presence of $25 \mu \mathrm{g} / \mathrm{mL}$ of $\mathrm{c}(\mathrm{RGDFK})-\mathrm{NPs}$ or cNPs, then the iron core was detected with the Prussian blue histological staining (blue), then the cells were counterstained with eosin (pink). Scale bar: $40 \mu \mathrm{m}$.

The biocompatibility of the USPIO NPs functionalized with the PEG oligomers 6 and 7 was assessed using the hemolytic assays. ${ }^{36}$ The hemolytic potential, defined as the lysis of red blood cells, is an adverse event which might occur upon exposure to NPs. ${ }^{37}$ Uncoated USPIO NPs showed a high hemolytic potential, causing the lysis of $100 \%$ of human red blood cells after $2 \mathrm{~h}$ exposure (Fig. 2). Functionalization of the USPIO NPs with PEG molecules $\mathbf{6}$ and $\mathbf{7}$ drastically improved the biocompatibility of the resulting nanomaterials as no hemolytic effect could be observed after $2 \mathrm{~h}$ exposure at a concentration of $50 \mu \mathrm{g} / \mathrm{mL}$. The same behavior was observed for the USPIO NPs functionalized with the $\alpha_{v} \beta_{3}$ integrin-targeting cRGDfK ligand (data not shown).

As the $\alpha_{v} \beta_{3}$ integrin was reported as an important biomarker for the detection of primary cancer and metastasis, ${ }^{38}$ we further addressed the ability of functionalized USPIO NPs to specifically target human derived cancer cells expressing this membrane receptor, through recognition of the cyclo [Arg-Gly-Asp-D-PheLys] sequence at the surface of NPs. The human PC3 prostate cancer cells, which express the $\alpha_{v} \beta_{3}$ integrin, ${ }^{39}$ and the MCF-7 breast cancer cells, which do not express the $\alpha_{v} \beta_{3}$ integrin, ${ }^{23}$ were selected as positive and negative control cells, respectively. The presence of USPIO NPs was detected histologically using the Prussian blue staining. ${ }^{40}$ None of the cells recognized cNPs. Upon exposure to USPIO NPs functionalized with c(RGDfK), PC3 cells showed a clear binding of the $\mathrm{c}(\mathrm{RGDfK})$-functionalized USPIO NPs, close to the cell adhesive contact (Fig. 3). Notably, a similar treatment of MCF-7 cells did not result in any significant binding of the functionalized NPs.

In summary, a fast and convenient large scale synthesis of heterobifunctional PEG oligomers suitable for silanization of USPIO NPs was developed. Differentiation of the hydroxyl ends of commercial PEG 2000 was achieved through selective reduction of a diazide intermediate. The resulting PEG derivatives allowed both the modification of the surface of metal oxide nanoparticles and the conjugation of bio-active molecules. For instance, magnetite NPs were efficiently pegylated with oligomers $\mathbf{6}$ and 7, allowing further conjugation with $\mathrm{c}(\mathrm{RGDfK})$ derivative $\mathbf{9}$ through click reaction. The resulting functionalized nanoparticles did not show any hemolytic effect on human red blood cells and demonstrated specific binding to human cancer cells expressing the $\alpha_{\mathrm{v}} \beta_{3}$ integrin, an important biomarker of human cancer. In view of the many imaging applications of iron oxide-based nanomaterials, ${ }^{41-46}$ the functionalization procedures described herein offers new possibilities for biomedical applications based on NPs.

\section{Acknowledgments}

This work was supported by the European Commission FP7 NAMDIATREAM project (EU NMP4-LA-2010-246479) and by the INTERREG IV NAOMI project. The authors thank Dr. Catherine Schütz and MER Dr Christine Wandrey for helpful discussions and access to analytical equipment. We also thank Mr. Martial Rey and Dr. Pascal Miéville (NMR spectrometry service, ISIC, EPFL), Dr. Laure Menin and Mr. Francisco Sepulveda (MS service, ISIC, EPFL) for technical help.

\section{Supplementary data}

Supplementary data (synthetic procedures, characterization of new compounds) associated with this article can be found, in the online version, at http://dx.doi.org/10.1016/j.bmcl.2013.06.037.

\section{References and notes}

1. Thompson, M. S.; Valada, T. P.; Valada, M. L.; Lin, Y.; Riffle, J. S. Polymers 2008, $49,345$.

2. Safavy, A.; Raisch, K. P.; Khazaeli, M. B.; Buchsbaum, D. J.; Bonner, J. A. J. Med. Chem. 1999, 42, 4919.

3. Oishi, M.; Hayashi, H.; Iijima, M.; Nagasaki, Y. J. Mater. Chem. 2007, 17, 3720.

4. Hoang, B.; Lee, H.; Reilly, R. M.; Allen, C. Mol. Pharm. 2009, 6, 581.

5. Liu, H. W.; Chen, C. H.; Tsai, C. L.; Lin, I. H.; Hsiue, G. H. Tissue Eng. 2007, 13, 1113. 
6. Ochs, C. J.; Such, G. K.; Städler, B.; Caruso, F. Biomacromolecules 2008, 9, 3389

7. Magadala, P.; Amiji, M. APPS J. 2008, 10, 565.

8. Oishi, M.; Hayashi, H.; Itaka, K.; Kataoka, K.; Nagasaki, Y. Colloid Polym. Sci. 2007, 285, 1055.

9. Akiyama, Y.; Otsuka, H.; Nagasaki, Y.; Kato, M.; Kataoka, K. Bioconjugate Chem. 2000, $11,947$.

10. Ishii, T.; Yamada, M.; Hirase, T.; Nagasaki, Y. Polym. J. 2005, 37, 221.

11. Zeng, F.; Allen, C. Macromolecules 2006, 39, 6391

12. Hiki, S.; Kataoka, K. Bioconjugate Chem. 2007, 18, 2191.

13. Li, Z.; Chau, Y. Polym. Chem. 2010, 1, 1599.

14. Li, Z.; Chau, Y. Bioconjugate Chem. 2011, 22, 518.

15. Won, C.-Y. Polym. Bull. 2004, 52, 109.

16. Kaiser, K.; Marek, M.; Haselgrübler, T.; Schindler, H.; Gruber, H. J. Bioconjugate Chem. 1997, 8, 545.

17. Lu, C.; Zhong, W. Polymers 2010, 2, 407.

18. Mahou, R.; Wandrey, C. Polymers 2012, 4, 561.

19. Bettinger, T.; Remy, J.-S.; Erbacher, P.; Behr, J.-P. Bioconjugate Chem. 1998, 9 842 .

20. Milner, R.; Campbell, I. L. J. Neurosci. Res. 2002, 69, 286

21. Jin, H.; Varner, J. Br. J. Cancer 2004, 90, 561.

22. Oba, M.; Aoyagi, K.; Miyata, K.; Matsumoto, Y.; Itaka, K.; Nishiyama, N.; Yamasaki, Y.; Koyama, H.; Kataoka, K. Mol. Pharm. 2008, 5, 1080.

23. Zako, T.; Nagata, H.; Terada, N.; Utsumi, A.; Sakono, M.; Yohda, M.; Ueda, H.; Soga, K.; Maeda, M. Biochem. Biophys. Res. Commun. 2009, 381, 54.

24. Yan, Y.; Chen, K.; Yang, M.; Sun, X.; Liu, S.; Chen, X. Amino Acids 2011, 41, 439

25. Zhou, A.; Wei, Y.; Wu, B.; Chen, Q.; Xing, D. Mol. Pharm. 2012, 9, 1580

26. Shenoy, D.; Fu, W.; Li, J.; Crasto, C.; Jones, G.; DiMarzio, C.; Sridhar, S.; Amiji, M. Int. J. Nanomed. 2006, $1,51$.

27. Li, J.; Crasto, C. F.; Weinberg, J. S.; Amiji, M.; Shenoy, D.; Sridhar, S.; Bubley, G. J.; Jones, G. B. Bioorg. Med. Chem. Lett. 2005, 15, 5558.

28. Kim, J.; Kim, H. S.; Lee, N.; Kim, T.; Kim, H.; Yu, T.; Song, I. C.; Moon, W. K. Hyeon, T. Angew. Chem., Int. Ed. 2008, 47, 8438.

29. Schladt, T. D.; Schneider, K.; Schild, H.; Tremel, W. Dalton Trans. 2011, 40, 6315

30. Yuen, A. K. L.; Hutton, G. A.; Masters, A. F.; Maschmeyer, T. Dalton Trans. 2012 41, 2545.

31. Mazur, M.; Barras, A.; Kuncser, V.; Galatanu, A.; Zaitzev, V.; Turcheniuk, K. V.; Woisel, P.; Lyskawa, J.; Laure, W.; Siriwardena, A.; Boukherroub, R.; Szunerits, S. Nanoscale 2013, 5, 2692.
32. Shultz, M. D.; Reveles, J. U.; Khanna, S. N.; Carpenter, E. E. J. Am. Chem. Soc. 2007, 129, 2482.

33. Borcard, F.; Staedler, D.; Comas, H.; Juillerat, F. K.; Sturzenegger, P. N.; Heuberger, R.; Gonzenbach, U. T.; Juillerat-Jeanneret, L.; Gerber-Lemaire, S. J. Med. Chem. 2012, 55, 7988.

34. Thöm, V. J.; Hosken, G. D.; Hancock, R. D. Inorg. Chem. 1985, 24, 3378.

35. Murti, Y.; Agnihotri, R.; Pathak, D. Am. J. Chem. 2011, 2, 42.

36. The hemolysis assay was performed essentially as follows: Fresh human blood was obtained from leftovers of analytical blood with normal values, the plasma was removed by centrifugation and blood cells were diluted 1:10 in PBS (phosphate buffered saline). The cells were incubated for $2 \mathrm{~h}$ either with $50 \mu \mathrm{g} /$ $\mathrm{mL}$ of the different USPIO NPs or with nanopure water as a positive control and PBS as a negative control. For the quantification of hemolysis, the cells were centrifuged and the absorbance of the upper layers was measured at $540 \mathrm{~nm}$ in an absorbance multi-well plate reader (Synergy HT, BioTek). The hemolysis percentage of the samples was determined by comparing the absorbance of cells exposed to PBS or to the USPIO NPs. Experiments were conducted in triplicate wells and repeated twice. Means \pm SD were calculated.

37. He, Q.; Zhang, J.; Shi, J.; Zhu, Z.; Zhang, L.; Bu, W.; Guo, L.; Chen, Y. Biomaterials 2010, 31, 1085.

38. Arosio, D.; Manzoni, L.; Araldi, E. M.; Caprini, A.; Monferini, E.; Scolastico, C. Bioconjugate Chem. 2009, 20, 1611.

39. Arosio, D.; Manzoni, L.; Araldi, E. M. V.; Scolastico, C. Bioconjugate Chem. 2011 $22,664$.

40. Schlorf, T.; Meincke, M.; Kossel, E.; Glüer, C.-C.; Jansen, O.; Mentlein, R. Int. J. Mol. Sci. 2011, 12, 12.

41. Schraa, A. J.; Kok, R. J.; Moorlag, H. E.; Bos, E. J.; Proost, J. H.; Meijer, D. K.; de Leij, L. F.; Molema, G. Int. J. Cancer 2002, 102, 469.

42. Zitzmann, S.; Ehemann, V.; Schwab, M. Cancer Res. 2002, 62, 5139.

43. Haubner, R.; Wester, H. J.; Weber, W. A.; Mang, C.; Ziegler, S. I.; Goodman, S. L. Senekowitsch-Schmidtke, R.; Kessler, H.; Schwaiger, M. Cancer Res. 2001, 61 1781.

44. Su, Z. F.; Liu, G.; Gupta, S.; Zhu, Z.; Rusckowski, M.; Hnatowich, D. J. Bioconjugate Chem. 2002, 13, 561.

45. Lee, J. H.; Lee, K.; Moon, S. H.; Lee, Y.; Park, T. G.; Cheon, J. Angew. Chem., Int. Ed. 2009, 48, 4174

46. Lee, H. Y.; Li, Z.; Chen, K.; Hsu, A. R.; Xu, C.; Xie, J.; Sun, S.; Chen, X. J. Nucl. Med. 2008, 49, 1371 